\title{
Fibrinogen and red blood cells in venous thrombosis
}

\author{
Maria M. Aleman, Bethany L. Walton, James R. Byrnes, and Alisa S. Wolberg \\ Department of Pathology and Laboratory Medicine, University of North Carolina at Chapel Hill, \\ and McAllister Heart Institute, University of North Carolina at Chapel Hill
}

Abstract

Deep vein thrombosis and pulmonary embolism, collectively termed venous thromboembolism (VTE), affect over 1 million Americans each year. VTE is triggered by inflammation and blood stasis leading to the formation of thrombi rich in fibrin and red blood cells (RBCs). However, little is known about mechanisms regulating fibrin and $\mathrm{RBC}$ incorporation into venous thrombi, or how these components mediate thrombus size or resolution. Both elevated circulating fibrinogen (hyperfibrinogenemia) and abnormal fibrin(ogen) structure and function, including increased fibrin network density and resistance to fibrinolysis, have been observed in plasmas from patients with VTE. Abnormalities in RBC number and/or function have also been associated with VTE risk. RBC contributions to VTE are thought to stem from their effects on blood viscosity and margination of platelets to the vessel wall. More recent studies suggest RBCs also express phosphatidylserine, support thrombin generation, and decrease fibrinolysis. RBC interactions with fibrin(ogen) and cells, including platelets and endothelial cells, may also promote thrombus formation. The contributions of fibrin(ogen) and RBCs to the pathophysiology of VTE warrants further investigation.

\begin{abstract}
Venous thrombosis/thromboembolism (deep vein thrombosis and/or pulmonary embolism; VTE), affects over 1 million Americans each year [1]. VTE is triggered by intravascular activation of coagulation and thrombin-mediated intraluminal fibrin deposition [2-4]. Red blood cells (RBCs) are thought to be incorporated into venous thrombi via passive trapping in the growing fibrin network, culminating in the production of a RBC- and fibrin-rich venous thrombus. However, little is known about mechanisms regulating fibrin deposition and $R B C$ incorporation into venous thrombi, or how fibrin(ogen) and RBCs contribute to venous thrombus size or resolution. This review will discuss how fibrinogen, RBCs, and interactions between the two may contribute to VTE.
\end{abstract}

(C) 2014 Elsevier Ltd. All rights reserved.

Address correspondence to: Alisa S. Wolberg, Ph. D., Department of Pathology and Laboratory Medicine, University of North Carolina at Chapel Hill, 815 Brinkhous-Bullitt Building, CB \#7525, Chapel Hill, NC 27599-7525, phone: (919) 966-8430, fax: (919) 966-6718, alisa_wolberg@med.unc.edu.

Publisher's Disclaimer: This is a PDF file of an unedited manuscript that has been accepted for publication. As a service to our customers we are providing this early version of the manuscript. The manuscript will undergo copyediting, typesetting, and review of the resulting proof before it is published in its final citable form. Please note that during the production process errors may be discovered which could affect the content, and all legal disclaimers that apply to the journal pertain.

None. 


\section{VTE}

As opposed to arterial thrombosis, which arises following atherosclerotic plaque rupture and exposure of subendothelial cells to blood in high shear (500-1500 s ${ }^{-1}$ ), VTE is often associated with plasma hypercoagulability and thought to be triggered by expression of cell adhesion molecules and procoagulant activity on intact, but dysfunctional endothelium in low shear (10-100 s "- "stasis"). Consequently, whereas arterial thrombi (so called "white clots") are platelet-rich, venous thrombi ("red clots") are high in RBC and fibrin content (Figure).

VTE is thought to initiate in the hypoxic environment of venous valve pockets [2], where intravascular activation of coagulation triggers thrombin-mediated fibrin deposition. Adhesion of neutrophils and monocytes to activated endothelium is a necessary initial step for venous thrombus formation [3, 4]. Subsequently, myeloid cell expression of TF and neutrophil extracellular traps promote both extrinsic and intrinsic coagulation [3, 4]. Abnormal expression of both cellular and plasma procoagulant activity have been implicated as risk factors for development of VTE. Additional common risk factors for VTE include smoking, trauma, prolonged immobility, infection, and cancer. Chronic venous insufficiency, post-thrombotic syndrome, and pulmonary embolism are common sequelae.

\section{Fibrinogen}

Fibrinogen is a $340 \mathrm{kD}$ plasma glycoprotein that circulates at $2-5 \mathrm{mg} / \mathrm{mL}$. Fibrinogen is comprised of 2 pairs each of $\mathrm{Aa}, \mathrm{B} \beta$, and $\gamma$ chains arranged as a rod-like protein. When coagulation is activated, thrombin cleaves fibrinopeptides from the N-termini of the Aa and $\mathrm{B} \beta$ chains permitting polymerization of fibrin monomers into an insoluble fibrin network [5]. The fibrin network is stabilized by the transglutaminase enzyme factor XIIIa (FXIIIa), which cross-links $\gamma-\gamma$ and $\gamma$-a chains within the network, as well as antifibrinolytic proteins (e.g., a2-antiplasmin) to the network [6]. The fibrin network serves as a scaffold for the binding of endothelial cells, leukocytes, platelets, and plasma proteins to the clot.

Abnormalities in fibrin(ogen) level and/or function are well-established risk factors for VTE. An elevated plasma fibrin(ogen) level (hyperfibrinogenemia, $>4 \mathrm{mg} / \mathrm{mL}$ ) significantly increases the risk of VTE; this risk is concentration-dependent and present across genders [7]. Using an intravenous infusion strategy to increase levels of circulating fibrinogen in mice, we observed that hyperfibrinogenemic mice exhibited a shorter time to vessel occlusion, increased thrombus fibrin content, and increased resistance of thrombi to thrombolysis compared to controls [8]. These findings suggest hyperfibrinogenemia is not merely a biomarker of thrombotic risk, but is causative in the etiology of venous thrombosis.

Several studies have correlated increased risk of VTE with increased fibrin network density and increased resistance of plasma clots to fibrinolysis [9, 10]. These effects are likely mediated through multiple mechanisms. First, fibrin network structure reflects the fibrinogen concentration, and the presence of elevated fibrinogen increases fibrin network density, clot stiffness, and the resistance of clots to fibrinolysis [8]. Second, fibrin network structure is highly sensitive to the thrombin concentration present during fibrin polymerization [11]. Hypercoagulable states, such as hyperprothrombinemia, that lead to 
rapid production of high levels of thrombin produce dense fibrin networks composed of abnormally thin fibers $[12,13]$. In addition to the effects of plasma composition on fibrin quality, fibrin(ogen) bares binding sites for cellular integrins, including $a \operatorname{IIb} \beta 3, a \mathrm{M} \beta 2$, and $a V \beta 3$, and interactions between the fibrin network and cells increase fibrin network density and the resistance of clots to fibrinolysis [14]. In situ thrombin generation on the surface of vascular cells also increases fibrin network density, independent of integrin-fibrin(ogen) binding $[15,16]$. Fibrin(ogen) engagement of leukocyte integrins also upregulates NF- $\mathrm{kB}$ signaling [17] and augments TF expression [18], providing positive feedback for the thrombin-mediated regulation of fibrin network structure.

Defects in fibrinogen function that result from congenital mutations (dysfibrinogenemia) are also associated with VTE [19]. The prothrombotic nature of dysfibrinogenemias may relate to the reduced ability of fibrin(ogen) to bind and sequester thrombin that leads to excessive thrombin in circulation, defective binding of tissue plasminogen activator or plasminogen to the fibrin network, and/or abnormal fibrin network structure and resistance to lysis. In one notable example, a high incidence of fibrinogen mutations has been observed in patients with chronic thromboembolic pulmonary hypertension (CTEPH), suggesting that abnormal fibrin structure and/or stability contribute to persistent pulmonary emboli and consequently, the development of CTEPH [20]. Together these findings place fibrin formation and quality at the nexus of procoagulant activity and thrombus formation.

\section{RBCs}

RBCs are flexible, biconcave, anucleate cells derived from bone marrow. RBCs are the most abundant cell type in blood, and circulate at $\sim 4.2-6.1 \times 10^{9} / \mathrm{mL}$ in humans; numbers are slightly higher in men than women. Primary RBC function is oxygen transport via its hemoglobin-rich cytoplasm. RBCs are readily identifiable by most macroscopic and microscopic techniques, but are often discarded during blood processing for hematological tests. However, this centrifugal waste may be more important than realized as recent studies suggest RBCs are not just passive bystanders, but play an active role in coagulation.

A growing body of evidence suggests that abnormal RBC quantity and quality contribute to clot formation in vivo. Bleeding times shorten as hematocrit rises in anemic, normal, and polycythemic individuals [21], and elevated RBC levels are associated with increased risk of venous thrombosis in patients with polycythemia vera or patients on erythropoietin [22, 23]. Patients with sickle cell disease (SCD) have abnormal hemoglobin polymerization resulting in dysfunctional RBCs with a characteristic "sickled" appearance; notably, SCD patients have an increased incidence of large-vessel thrombosis, including pulmonary embolism [24]. However, an etiologic role for RBCs in VTE remains unclear.

RBCs may contribute to thrombosis in several ways. First, RBCs increase blood viscosity and marginate platelets toward the endothelium, placing them in close proximity to sites of vascular trauma. Second, a subfraction of RBCs express phosphatidylserine on their surface and in vitro studies show that RBCs can support thrombin generation, suggesting RBCs may promote fibrin deposition during venous thrombosis [25, 26]. Interestingly, RBC phosphatidylserine expression correlates with endogenous markers of activation of 
coagulation in patients with SCD [27]. Third, once in the clot, RBCs appear to exert direct, complex effects on clot structure and stability. For example, RBCs have been shown to increase the size of pores in the fibrin network [28], but decrease fibrin network permeability [29]. Finally, the presence of RBCs in clots suppresses plasmin generation and reduces clot dissolution [30]. These observations suggest that decreasing thrombus RBC content would accelerate thrombus resolution.

\section{RBC interactions with vascular cells and fibrin(ogen) during venous thrombogenesis}

Little is known about how RBCs become incorporated into venous thrombi. The existing paradigm asserts that during venous thrombosis, RBCs become sterically trapped in the growing fibrin network. However, increasing evidence suggests RBCs are incorporated into thrombi via specific interactions. RBCs interact with activated endothelial cells and this interaction was recently demonstrated in a study of arterial thrombosis in which RBCs were the first cells to adhere to $\mathrm{FeCl}_{3}$-treated intact endothelium, prior to the arrival of platelets [31]. Integrin-mediated interactions between RBCs and leukocytes and platelets may also lead to their incorporation into thrombi. RBCs bind to platelet aIIb $\beta 3$ and this interaction depends on the platelet activation state, is metal ion-dependent, and can be inhibited by arginylglycylaspartic acid-containing peptide, anti-ICAM-4 antibody, or soluble fibrinogen [32, 33]. RBC ICAM-4 also interacts with leukocyte $\beta 1$ and $\beta 2$ integrins [34].

Interestingly, RBCs and fibrin can be found in a "brick-and-mortar" arrangement within venous thrombi (Figure), raising the possibility that these components directly interact during venous thrombogenesis. Indeed, RBCs have been shown to interact specifically with fibrin(ogen), with $\sim 20,000$ binding sites/RBC and $\mathrm{Kd} \sim 1.3 \mu \mathrm{M}$ [35]. Two potential receptors on RBCs have been implicated in fibrin(ogen)-RBC interactions: $\beta 3$ or a $\beta 3$-like molecule [36] and the integrin-associated protein CD47 [37]. Since CD47 was originally identified for its interaction with av $\beta 3$, aIIb $\beta 3$, and $a 2 \beta 1$ integrins, it is possible that the fibrinogenbinding site on RBCs consists of a complex of both of these molecules. Recent intriguing data from our laboratory suggest that fibrin(ogen)-mediated transport of FXIII(a) to the clot is necessary for RBC retention in thrombi; compared to wild type mice, mice with reduced or delayed FXIIIa activation produce smaller venous thrombi with reduced RBC content [38]. Whether FXIIIa activity is necessary to stabilize the fibrin network or directly crosslink RBCs into the clot remains to be determined.

\section{Conclusions and Future Directions}

Together, these observations imply that fibrin(ogen) and RBCs are not only major components of venous thrombi and determinants of VTE risk, but also actively contribute to the pathophysiology of VTE. Clearly, continued research into the prothrombotic nature of both RBCs and fibrin(ogen) is warranted, with a particular emphasis on the physical and biochemical interactions between RBCs, fibrin(ogen), and vascular cells. Disrupting the incorporation of fibrin(ogen) and/or RBCs into venous thrombi has high potential therapeutic value for reducing VTE and VTE-related sequelae. 


\section{Acknowledgments}

\section{SOURCES OF FUNDING}

The authors are supported by National Institutes of Health grants R01HL094740 (to ASW), F31HL112608 (to MMA), and T32HL069768 (to the University of North Carolina and BLW).

\section{REFERENCES}

1. Heit JA. Venous thromboembolism epidemiology: implications for prevention and management. Semin Thromb Hemost. 2002; 28(Suppl 2):3-13. [PubMed: 12073175]

2. Sevitt S. The structure and growth of valve-pocket thrombi in femoral veins. J Clin Pathol. 1974; 27:517-528. [PubMed: 4138834]

3. von Bruhl ML, Stark K, Steinhart A, Chandraratne S, Konrad I, Lorenz M, et al. Monocytes, neutrophils, and platelets cooperate to initiate and propagate venous thrombosis in mice in vivo. $\mathrm{J}$ Exp Med. 2012; 209:819-835. [PubMed: 22451716]

4. Darbousset R, Thomas GM, Mezouar S, Frere C, Bonier R, Mackman N, et al. Tissue factorpositive neutrophils bind to injured endothelial wall and initiate thrombus formation. Blood. 2012; 120:2133-2143. [PubMed: 22837532]

5. Lord ST. Molecular mechanisms affecting fibrin structure and stability. Arterioscler Thromb Vasc Biol. 2011; 31:494-499. [PubMed: 21325671]

6. Bagoly Z, Koncz Z, Harsfalvi J, Muszbek L. Factor XIII, clot structure, thrombosis. Thromb Res. 2012; 129:382-387. [PubMed: 22197181]

7. van Hylckama, Vlieg A.; Rosendaal, FR. High levels of fibrinogen are associated with the risk of deep venous thrombosis mainly in the elderly. J Thromb Haemost. 2003; 1:2677-2678. [PubMed: 14675106]

8. Machlus KR, Cardenas JC, Church FC, Wolberg AS. Causal relationship between hyperfibrinogenemia, thrombosis, and resistance to thrombolysis in mice. Blood. 2011; 117:49534963. [PubMed: 21355090]

9. Undas A, Zawilska K, Ciesla-Dul M, Lehmann-Kopydlowska A, Skubiszak A, Ciepluch K, et al. Altered fibrin clot structure/function in patients with idiopathic venous thromboembolism and in their relatives. Blood. 2009; 114:4272-4278. [PubMed: 19690336]

10. Lisman T, de Groot PG, Meijers JC, Rosendaal FR. Reduced plasma fibrinolytic potential is a risk factor for venous thrombosis. Blood. 2005; 105:1102-1105. [PubMed: 15466929]

11. Wolberg AS. Thrombin generation and fibrin clot structure. Blood Rev. 2007; 21:131-142. [PubMed: 17208341]

12. Wolberg AS, Monroe DM, Roberts HR, Hoffman M. Elevated prothrombin results in clots with an altered fiber structure: a possible mechanism of the increased thrombotic risk. Blood. 2003; 101:3008-3013. [PubMed: 12506014]

13. Aleman MM, Walton BL, Byrnes JR, Wang JG, Heisler MJ, Machlus KR, et al. Elevated prothrombin promotes venous, but not arterial, thrombosis in mice. Arterioscler Thromb Vasc Biol. 2013; 33:1829-1836. [PubMed: 23723374]

14. Jerome WG, Handt S, Hantgan RR. Endothelial cells organize fibrin clots into structures that are more resistant to lysis. Microsc Microanal. 2005; 11:268-277. [PubMed: 16060980]

15. Campbell RA, Overmyer KA, Selzman CH, Sheridan BC, Wolberg AS. Contributions of extravascular and intravascular cells to fibrin network formation, structure, and stability. Blood. 2009; 114:4886-4896. [PubMed: 19797520]

16. Collet JP, Montalescot G, Lesty C, Weisel JW. A structural and dynamic investigation of the facilitating effect of glycoprotein IIb/IIIa inhibitors in dissolving platelet-rich clots. Circ Res. 2002; 90:428-434. [PubMed: 11884372]

17. Guo M, Sahni SK, Sahni A, Francis CW. Fibrinogen regulates the expression of inflammatory chemokines through NF-kappaB activation of endothelial cells. Thrombosis and haemostasis. 2004; 92:858-866. [PubMed: 15467918] 
18. Fan ST, Edgington TS. Coupling of the adhesive receptor CD11b/CD18 to functional enhancement of effector macrophage tissue factor response. The Journal of clinical investigation. 1991; 87:5057. [PubMed: 1670636]

19. de Moerloose P, Casini A, Neerman-Arbez M. Congenital fibrinogen disorders: an update. Semin Thromb Hemost. 2013; 39:585-595. [PubMed: 23852822]

20. Morris TA, Marsh JJ, Chiles PG, Magana MM, Liang NC, Soler X, et al. High prevalence of dysfibrinogenemia among patients with chronic thromboembolic pulmonary hypertension. Blood. 2009; 114:1929-1936. [PubMed: 19420351]

21. Ho CH. The hemostatic effect of packed red cell transfusion in patients with anemia. Transfusion. 1998; 38:1011-1014. [PubMed: 9838929]

22. Dicato M. Venous thromboembolic events and erythropoiesis-stimulating agents: an update. Oncologist. 2008; 13(Suppl 3):11-15. [PubMed: 18458119]

23. Spivak JL. Polycythemia vera: myths, mechanisms, and management. Blood. 2002; 100:42724290. [PubMed: 12393615]

24. Novelli EM, Huynh C, Gladwin MT, Moore CG, Ragni MV. Pulmonary embolism in sickle cell disease: a case-control study. J Thromb Haemost. 2012; 10:760-766. [PubMed: 22417249]

25. Peyrou V, Lormeau JC, Herault JP, Gaich C, Pfliegger AM, Herbert JM. Contribution of erythrocytes to thrombin generation in whole blood. Thromb Haemost. 1999; 81:400-406. [PubMed: 10102469]

26. Whelihan MF, Zachary V, Orfeo T, Mann KG. Prothrombin activation in blood coagulation: the erythrocyte contribution to thrombin generation. Blood. 2012; 120:3837-3845. [PubMed: 22968460]

27. Setty BN, Rao AK, Stuart MJ. Thrombophilia in sickle cell disease: the red cell connection. Blood. 2001; 98:3228-3233. [PubMed: 11719358]

28. Carr ME Jr, Hardin CL. Fibrin has larger pores when formed in the presence of erythrocytes. The American journal of physiology. 1987; 253:H1069-H1073. [PubMed: 3688251]

29. van Gelder JM, Nair CH, Dhall DP. The significance of red cell surface area to the permeability of fibrin network. Biorheology. 1994; 31:259-275. [PubMed: 8729486]

30. Wohner N, Sotonyi P, Machovich R, Szabo L, Tenekedjiev K, Silva MM, et al. Lytic resistance of fibrin containing red blood cells. Arteriosclerosis, thrombosis, and vascular biology. 2011; 31:2306-2313.

31. Barr JD, Chauhan AK, Schaeffer GV, Hansen JK, Motto DG. Red blood cells mediate the onset of thrombosis in the ferric chloride murine model. Blood. 2013; 121:3733-3741. [PubMed: 23343833]

32. Hermand P, Gane P, Huet M, Jallu V, Kaplan C, Sonneborn HH, et al. Red cell ICAM-4 is a novel ligand for platelet-activated alpha IIbbeta 3 integrin. J Biol Chem. 2003; 278:4892-4898. [PubMed: 12477717]

33. Goel MS, Diamond SL. Adhesion of normal erythrocytes at depressed venous shear rates to activated neutrophils, activated platelets, and fibrin polymerized from plasma. Blood. 2002; 100:3797-3803. [PubMed: 12393714]

34. Hermand P, Huet M, Callebaut I, Gane P, Ihanus E, Gahmberg CG, et al. Binding sites of leukocyte beta 2 integrins (LFA-1, Mac-1) on the human ICAM-4/LW blood group protein. J Biol Chem. 2000; 275:26002-26010. [PubMed: 10846180]

35. Lominadze D, Dean WL. Involvement of fibrinogen specific binding in erythrocyte aggregation. FEBS Lett. 2002; 517:41-44. [PubMed: 12062406]

36. Carvalho FA, Connell S, Miltenberger-Miltenyi G, Pereira SV, Tavares A, Ariens RA, et al. Atomic force microscopy-based molecular recognition of a fibrinogen receptor on human erythrocytes. ACS Nano. 2010; 4:4609-4620. [PubMed: 20731444]

37. De Oliveira S, Vitorino de Almeida V, Calado A, Rosario HS, Saldanha C. Integrin-associated protein (CD47) is a putative mediator for soluble fibrinogen interaction with human red blood cells membrane. Biochim Biophys Acta. 2012; 1818:481-490. [PubMed: 22079249]

38. Aleman MM, Byrnes JR, Wang J-G, Mackman N, Degen JL, Flick MJ, et al. Fibrin crosslinking is required for retention of red blood cells in venous thrombi. Blood. 2013; 122:451. 


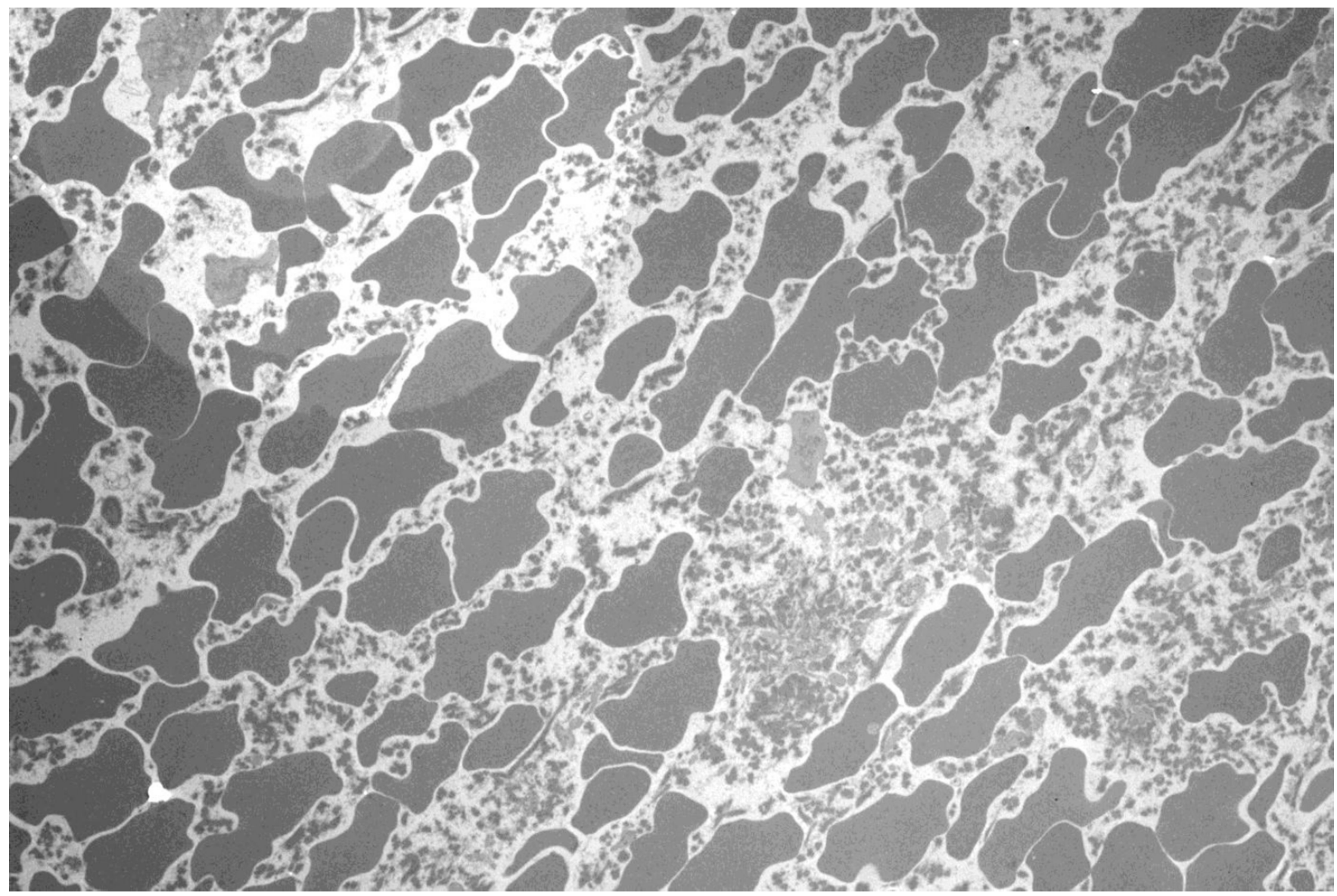

Figure. Human pulmonary embolus micrograph

Pulmonary embolus was collected at autopsy at UNC Hospitals and fixed in glutaraldehyde for transmission electron microscopy (2000X magnification). Note the "brick-and-mortar" organization of RBCs and fibrin within the thrombus. 